\title{
Seasonal, not annual precipitation drives community productivity across ecosystems
}

\author{
Todd M. P. Robinson, Kimberly J. La Pierre, Matthew A. Vadeboncoeur, Kerry M. Byrne, \\ Michell L. Thomey and Samantha E. Colby
}

T. M. P. Robinson (robin590@msu.edu), W. K. Kellogg Biological Station, Michigan State Univ., 3700 E. Gull Lake Dr. Hickory Corners, MI 49060, USA. - K. J. La Pierre, Dept of Ecology and Evolutionary Biology, Yale Univ., New Haven, CT 06511, USA. - M. A. Vadeboncoeur, Earth Systems Research Center, Univ. of New Hampshire, Durham, NH 03824, USA. - K. M. Byrne, Graduate Degree Program in Ecology, Colorado State Univ., Fort Collins, CO 80523, USA. - M. L. Thomey, Dept of Biology, Univ. of New Mexico, Albuquerque, NM 87131, USA. - S. E. Colby, Dept Botany and Plant Pathology, Oregon State Univ., Corvallis, OR 97331, USA.

\begin{abstract}
Understanding drivers of aboveground net primary production (ANPP) has long been a goal of ecology. Decades of investigation have shown total annual precipitation to be an important determinant of ANPP within and across ecosystems. Recently a few studies at individual sites have shown precipitation during specific seasons of the year can more effectively predict ANPP. Here we determined whether seasonal or total precipitation better predicted ANPP across a range of terrestrial ecosystems, from deserts to forests, using long-term data from 36 plant communities. We also determined whether ANPP responses were dependent on ecosystem type or plant functional group. We found that seasonal precipitation generally explained ANPP better than total precipitation. Precipitation in multiple parts of the growing season often correlated with ANPP, but rarely interacted with each other. Surprisingly, the amount of variation explained by seasonal precipitation was not correlated with ecosystem type or plant functional group. Overall, examining seasonal precipitation can significantly improve ANPP predictions across a broad range of ecosystems and plant types, with implications for understanding current and future ANPP variation. Further work examining precipitation timing relative to species phenology may further improve our ability to predict ANPP, especially in response to climate change.
\end{abstract}

Understanding the variable nature of aboveground net primary production (ANPP) is a fundamental goal in ecology (Sala and Austin 2000). Historically, studies of ANPP have focused on regional and global patterns, linking temporal changes in ANPP to abiotic factors, especially annual precipitation and temperature (Rosenzweig 1968, Leith and Whittaker 1975, Sala et al. 1988). These studies have increased our knowledge of carbon cycling, trophic interactions, and predictions of agricultural yields (McNaughton et al. 1989, Baker et al. 1993, Motha and Baier 2005). Recent predictions of altered precipitation patterns (Easterling et al. 2000, Weltzin et al. 2003, Diffenbaugh et al. 2005) have initiated new studies on how increased precipitation variability affects plant community dynamics (Heisler-White et al. 2009, Robinson and Gross 2010, Yang et al. 2011). While most studies have accounted for the effect of total annual precipitation on ANPP patterns (Lauenroth and Sala 1992, Ma et al. 2008), several site-specific studies have recently found that precipitation within specific segments of the year (hereafter 'seasonal precipitation') can explain the variation in yearly ANPP better than total precipitation for some ecosystems (Milchunas et al. 1994, Briggs and Knapp 1995, Jobbágy and
Sala 2000, Knapp et al. 2006, Chou et al. 2008, Muldavin et al. 2008, Xia et al. 2010, La Pierre et al. 2011). Climate models consistently project increased climate variability to include altered seasonal precipitation regimes (IPCC 2007, Schoof et al. 2010), therefore, it is essential to understand how seasonal precipitation affects ANPP across ecosystems. Changes in precipitation during a period when production is most sensitive to water availability may have a disproportionate impact on total annual production and potentially feedback to the global carbon cycle (Schimel et al. 2001).

While climate change is expected to alter precipitation regimes at a global scale, analysis of the effects of changes in seasonal precipitation on ANPP to date has generally been limited to single-system studies (Suttle et al. 2007, but see Vermeire et al. 2009) with no generalization across ecosystem types. Despite its importance, understanding changes in ANPP due to variability in precipitation across ecosystems is problematic because plant communities can differ in sensitivity to precipitation variability (i.e. rainuse efficiency, Huxman et al. 2004). For example, ANPP in desert and grassland ecosystems is highly sensitive to inter-annual rainfall variability but the magnitude of the change is likely limited by plant density. In contrast, solar 
radiation, nutrient supply, or growing season length may be more important in explaining ANPP in forested ecosystems that are characterized by high soil water content and low precipitation variability (Webb et al. 1978, 1983, Knapp and Smith 2001, Newman et al. 2006).

In addition to ecosystem type, differences in co-occurring plant functional groups within an ecosystem are also likely to interact with changes in the distribution of precipitation to control ANPP (Fay et al. 2002). For example, grasses generally have relatively shallow, fibrous root systems that take advantage of soil moisture at the surface, while shrubs and trees often have deeper or dimorphic root systems that can access both shallow and deep soil moisture (Walter 1979, Ogle and Reynolds 2004). In addition to plant functional groups at the same site using water from different depths along the soil profile (Schenk and Jackson 2002, Nippert and Knapp 2007), previous studies have also shown that they may be using precipitation from different parts of the growing season (Jobbágy and Sala 2000, Huenneke et al. 2002, Robertson et al. 2010) as well. It could be conjectured that specific plant functional groups may drive the patterns observed in the seasonal precipitationANPP relationship within a particular ecosystem, but play a minimal role in another ecosystem. On the other hand, particular functional group combinations may stabilize overall ANPP responses to precipitation fluctuations by varying in opposite directions. This community level stability could then mask the impacts of precipitation variability on the relative abundance of functional groups. If such a mechanism exists, then it would be important to understand how plant functional group productivity changes with seasonal rainfall distributions across a broad range of ecosystems.

Here we aim to examine:

1. whether the variability of ANPP is best explained by precipitation amounts in specific seasonal periods as opposed to total annual or total growing season precipitation for multiple ecosystem types across North America;

2. whether this sensitivity to precipitation at either the seasonal or annual level can be generalized across all ecosystems or if it varies by ecosystem type; and

3. whether the effects of seasonal precipitation vary across plant functional groups.

Across ecosystems, we predict that seasonal precipitation will show a stronger correlation with ANPP than total precipitation in arid and semiarid ecosystems (desert and xeric grassland) since water is the most limiting resource in these systems and because production is known to be sensitive and respond rapidly to changes in water availability (Huxman et al. 2004, Yang et al. 2011). We further predict that ANPP will be better predicted by precipitation during the growing season in mesic grassland ecosystems because precipitation inputs in these systems are similar to potential evapotranspiration. This leads to more intermittent periods of water limitation and a greater possibility of water storage from previous parts of the growing season. We predict that ANPP in forested ecosystems will correlate best with pre-season precipitation, which recharges deeper soil layers, or not respond to annual or seasonal precipitation at all.
We also predict that sensitivity to seasonal precipitation will vary between plant functional groups. Production of shallow-rooted species (annuals and grasses) may be more sensitive to precipitation during the growing season while deeper rooted species (perennial herbaceous and woody species) will be more sensitive to pre-season precipitation (Notaro et al. 2010).

\section{Methods}

\section{Site selection}

We chose sites from the Long-Term Ecological Research (LTER) network based on the availability of long-term $(\geq 10$ years) annual ANPP records from unmanipulated or minimally manipulated communities. Of the 26 LTER sites, 10 met our criteria and are included in our analysis (Table 1). These sites span a wide range of climatic and vegetation types across North America, from deserts to forests (Table 1). We included four additional sites, Capulin Volcano National Monument (CVO), Hopland Field Station (HOP), Teakettle Experimental Forest (TEA), and the US Sheep Experiment Station (USE), in the analysis to represent vegetation types not covered by LTER data meeting our criteria. Because some sites have multiple community types (e.g. grass and shrub dominated communities at the Sevilleta LTER; SEV) or multiple types of ANPP proxy data (e.g. litterfall and tree cores from different sites at Hubbard Brook Experimental Forest; HBR), we included a total of 36 communities in our analysis (Table 1). The locations of all of the included sites are shown in Supplementary material Appendix A1 Fig. A1.

\section{ANPP and precipitation data}

ANPP data characterized whole-growing-season production at all sites, though a variety of methods were employed (see Supplementary material Appendix A1 for specific details on ANPP collection and data processing at each site). In general, forested sites used dendrometers, increment cores and/or litterfall collection to determine ANPP, while herbaceous sites determined ANPP by clipping current-year aboveground biomass within a given area at ground level. However some sites, including Jornada Experimental Range (JRN), SEV and USE, used non-destructive measurements to determine ANPP (Huenneke et al. 2001, Muldavin et al. 2008). A subset of herbaceous-dominated sites separated biomass by functional type prior to weighing by growth form and/or life history; the communities with this level of data are noted in Table 1. ANPP data were divided by growth form (grass, forb, woody) in 14 communities and in seven of these the data were also divided by life-history (annual, perennial).

Precipitation data were collected daily from weather stations at or near each site (Supplementary material Appendix A1). We calculated total annual precipitation as the sum of all precipitation from the end of one growing season through the end of the next (Fig. 1). We calculated total annual precipitation based on a plant-centric 
Table 1. Study sites analyzed in this study, arranged from lowest to highest mean annual precipitation (MAP). Due to different methodologies in forested sites, we have not reported average ANPP values. More complete site descriptions are in Supplementary material Appendix A1.

\begin{tabular}{|c|c|c|c|c|c|c|c|c|c|}
\hline Site & $\begin{array}{l}\text { Average } \\
\text { ANPP } \\
\left(\mathrm{g} \mathrm{m}^{-2}\right) \\
\end{array}$ & $\begin{array}{l}\text { MAP } \\
(\mathrm{mm})\end{array}$ & $\mathrm{CV}$ & $\begin{array}{l}\text { Vegetation } \\
\text { type }\end{array}$ & $\begin{array}{l}\text { Community types } \\
\text { (where multiple) }\end{array}$ & $\begin{array}{l}\text { Growing } \\
\text { season } \\
\text { (DOY) }\end{array}$ & $\begin{array}{l}\text { Dataset } \\
\text { length }\end{array}$ & $\begin{array}{c}\text { Growth } \\
\text { form* }\end{array}$ & Lifespan* \\
\hline $\begin{array}{l}\text { Sevilleta National } \\
\text { Wildlife Refuge (SEV) }\end{array}$ & $63-99$ & 245 & 0.22 & $\begin{array}{l}\text { desert and } \\
\text { shrubland }\end{array}$ & $\begin{array}{l}\text { creosote shrubland, } \\
\text { black grama grassland }\end{array}$ & $84-278$ & 1999-2008 & yes & yes \\
\hline $\begin{array}{l}\text { Jornada Experimental } \\
\text { Range (JRN) }\end{array}$ & 68-104 & 269 & 0.32 & $\begin{array}{l}\text { desert and } \\
\text { shrubland }\end{array}$ & $\begin{array}{l}\text { black grama grassland, } \\
\text { mesquite shrubland, } \\
\text { creosote shrubland, } \\
\text { tarbush shrubland }\end{array}$ & 84-281 & 1990-2008 & no & no \\
\hline $\begin{array}{l}\text { Bonanza Creek } \\
\text { Experimental Forest } \\
\text { (BNZ) }\end{array}$ & & 269 & 0.17 & forest & $\begin{array}{l}\text { floodplain (early and } \\
\text { late succ.) upland } \\
\text { (early and late succ.) }\end{array}$ & $115-267$ & 1994-2008 & no & no \\
\hline $\begin{array}{l}\text { US Sheep Experiment } \\
\text { Station (USE) }\end{array}$ & 92 & 280 & 0.18 & shrubland & $\mathrm{n} / \mathrm{a}$ & $84-217$ & 1936-1954 & no & no \\
\hline $\begin{array}{l}\text { Shortgrass Steppe LTER } \\
\text { (SGS) }\end{array}$ & $13-26$ & 353 & 0.20 & grassland & ridgetop, midland, swale & $96-217$ & 1983-2006 & yes & yes \\
\hline $\begin{array}{l}\text { Capulin Volcano } \\
\text { National Monument } \\
\text { (CVO) }\end{array}$ & & 442 & 0.20 & shrubland & & $105-287$ & 1951-1991 & no & no \\
\hline $\begin{array}{l}\text { Konza Prairie Biological } \\
\text { Station (KNZ) }\end{array}$ & $332-567$ & 807 & 0.24 & grassland & $\begin{array}{l}\text { uplands and lowlands in } \\
\text { annual, } 4-y r \text {, and } \\
20-y r \text { burn regimes }\end{array}$ & $85-278$ & 1984-2008 & yes & no \\
\hline $\begin{array}{l}\text { Cedar Creek Ecosystem } \\
\text { Science Reserve (CDR) }\end{array}$ & $191-417$ & 815 & 0.20 & grassland & $\mathrm{n} / \mathrm{a}$ & $115-288$ & 1982-2006 & yes & yes \\
\hline $\begin{array}{l}\text { Kellogg Biological Station } \\
\text { (KBS) }\end{array}$ & $416-599$ & 855 & 0.25 & grassland & $\begin{array}{l}\text { early and mid } \\
\text { successional }\end{array}$ & $85-248$ & 1990-2008 & yes & yes \\
\hline $\begin{array}{l}\text { Hopland Field Station } \\
\text { (HOP) }\end{array}$ & 230 & 908 & 0.23 & grassland & $\mathrm{n} / \mathrm{a}$ & 288-156 & 1952-1966 & no & no \\
\hline $\begin{array}{l}\text { Teakettle Experimental } \\
\text { Forest (TEA) }\end{array}$ & & 1113 & 0.47 & forest & $\mathrm{n} / \mathrm{a}$ & $105-287$ & 1997-2008 & no & no \\
\hline Harvard Forest (HFR) & & 1119 & 0.16 & forest & $\begin{array}{l}\text { hemlock, hardwood, } \\
\text { mixed }\end{array}$ & $115-267$ & 1965-2007 & no & no \\
\hline $\begin{array}{l}\text { Hubbard Brook } \\
\text { Experimental Forest } \\
\text { (HBR) }\end{array}$ & & 1448 & 0.13 & forest & $\begin{array}{l}\text { northern hardwood } \\
\text { (1 area with cores, } \\
1 \text { with litter })\end{array}$ & $115-267$ & 1956-2005 & no & no \\
\hline $\begin{array}{l}\text { Coweeta Experimental } \\
\text { Forest (CWT) }\end{array}$ & & 1619 & 0.19 & forest & $\begin{array}{l}\text { oak-pine, cove } \\
\text { hardwoods, mixed } \\
\text { oak lowland, mixed } \\
\text { oak highland, } \\
\text { northern hardwoods }\end{array}$ & 115-297 & 1999-2008 & no & no \\
\hline
\end{tabular}

*Functional groups.

precipitation year rather than the calendar year, excluding months that could not influence measured ANPP (i.e. precipitation received after biomass collection). For example, in ecosystems with a spring-summer growing season and late September harvest, this would lead to plant-centric total 'annual' precipitation being summed from October of one year until September of the next year as opposed to January to December (Fig. 1). We determined the start and end of the growing season for each site based on a review of the literature or personal communication with principal investigators at the site (Table 1 ). We added ten days to the beginning and end of the growing season as a buffer against yearly variation in timing of emergence and senescence.

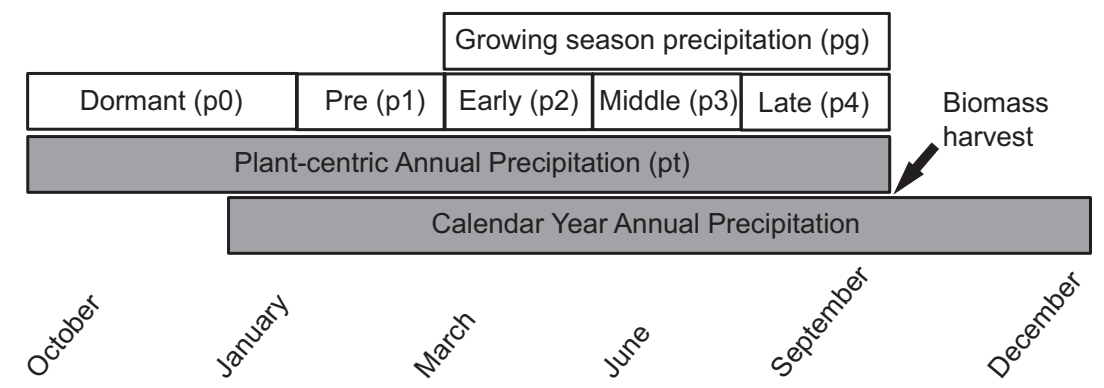

Figure 1. Yearly precipitation may be broken up in a variety of ways. We used a plant-centric definition for annual precipitation based on the growth period for a site and compared that to subdivisions of the year to determine which method better explained variation in aboveground net primary productivity. This is a generic example; growing season start and end dates were determined individually for each study site. 
We then sub-divided the plant-centric annual precipitation data into five periods for each site based on the site's growing season. First, we took the growing season for each site and split it into three equal parts (Fig. 1): an early growing season period (P2), a mid-growing season period (P3), and a late growing season period (P4). We defined the period immediately before the growing season as the 'pre-season' (P1, Fig. 1) that we hypothesized might affect emergence and initial plant growth due to recharging soil moisture immediately preceding the growing season. The length of this period was $1 / 3$ of the growing season length, the same length as the individual components (early, mid and late) of the growing season. The rest of the year was aggregated into a dormant period (P0, Fig. 1), to account for water storage since the end of the previous growing season. In addition to the three subdivisions of the growing season, we also used total growing season precipitation (Pg, Fig. 1) calculated as the sum of all precipitation during the early, middle, and late part of the growing season (P2-P4).

\section{Model development and analysis}

First we examined whether breaking annual precipitation into five distinct periods improved the fit of linear regression models relating precipitation to ANPP across communities in all of our sites. We used Akaike information criterion corrected for small sample sizes, AICc, to compare a model with all five periods to a model using only total precipitation, treating community as a random effect. While this allowed us to generalize across all communities, we also wanted to examine specific combination of seasonal periods with the idea that communities in different ecosystems might respond differently. We developed 17 biologically relevant models (Table 2) to determine the extent to which ANPP in different ecosystems correlated with annual precipitation, total growing season precipitation, or precipitation during individual or consecutive seasonal periods and their interactions. Twelve of the models included either total annual precipitation, growing season precipitation, or combinations of seasonal precipitation variables only, while five additional models included the interactions between consecutive seasonal periods. We only included combinations of sequential seasonal periods in these models, as we considered these periods to be the ones most likely to interact to influence ANPP. We did not include interactions between precipitation during the dormant period and any other season in the models, as we thought this interaction would be less likely to influence ANPP. Models did not include all combinations of seasonal precipitation variables or interactions in order to limit the identification of spurious correlations.

We compared all models using AICc, with the lowest value indicating the model that had the greatest support (Burnham and Anderson 2002). We considered models within two AICc points of each other to have equal empirical support (Burnham and Anderson 2002) and in these cases we report all tied models. We then examined the best models for statistical support and biological relevance. Models were considered to be statistically supported when they had a $\mathrm{p}<0.05$ and biologically relevant when they had an adjusted $R^{2} \geq 0.30$. We used adjusted $R^{2}$ to evaluate the explanatory power of our models because our models varied in the number variables. If the model(s) with the lowest AICc value for each community was statistically supported and biologically relevant, we report it as the best model for that community. We conducted these analyses for all communities on total ANPP data and in the subset of communities that had functional group data we ran the same analyses on functional group production. We ran all statistics in R 2.10.1 (R Foundation for Statistical Computing) using the packages lme4, qPCR, minpack.lm, and rgl.

\section{Results}

\section{ANPP response to seasonal and annual precipitation}

Breaking annual precipitation into five periods led to models with greater support from the data across all of the sites than simply using total annual precipitation $(\triangle \mathrm{AICc}=8)$, despite the penalty that AICc imposes for

Table 2. List of statistical models.

\begin{tabular}{|c|c|c|}
\hline No. & Model & Description \\
\hline 1 & $\mathrm{ANPP}=\mathrm{p} 1$ & pre-season only \\
\hline 2 & $\mathrm{ANPP}=\mathrm{p} 2$ & early growing season only \\
\hline 3 & $\mathrm{ANPP}=\mathrm{p} 3$ & mid-growing season only \\
\hline 4 & $\mathrm{ANPP}=\mathrm{p} 4$ & late growing season only \\
\hline 5 & $\mathrm{ANPP}=\mathrm{p} 2+\mathrm{p} 3$ & early and mid-growing season \\
\hline $5 a$ & $\mathrm{ANPP}=\mathrm{p} 2+\mathrm{p} 3+\mathrm{p} 2 * \mathrm{p} 3$ & early and mid-growing season, plus interaction \\
\hline 6 & $\mathrm{ANPP}=\mathrm{p} 3+\mathrm{p} 4$ & mid- and late growing season \\
\hline $6 a$ & $\mathrm{ANPP}=\mathrm{p} 3+\mathrm{p} 4+\mathrm{p} 3 * \mathrm{p} 4$ & mid- and late growing season, plus interaction \\
\hline 7 & $\mathrm{ANPP}=\mathrm{p} 1+\mathrm{p} 2$ & pre-season and early growing season \\
\hline $7 a$ & $\mathrm{ANPP}=\mathrm{p} 1+\mathrm{p} 2+\mathrm{p} 1 * \mathrm{p} 2$ & pre-season and early growing season, plus interaction \\
\hline 8 & $\mathrm{ANPP}=\mathrm{p} 0$ & dormant season only \\
\hline 9 & $\mathrm{ANPP}=\mathrm{p} 2+\mathrm{p} 3+\mathrm{p} 4$ & all three segments of the growing season \\
\hline 9a & $\mathrm{ANPP}=\mathrm{p} 2+\mathrm{p} 3+\mathrm{p} 4+\mathrm{p} 2 * \mathrm{p} 3+\mathrm{p} 3 * \mathrm{p} 4$ & all three segments of the growing season, plus interactions \\
\hline 10 & $\mathrm{ANPP}=\mathrm{p} 0+\mathrm{p} 1+\mathrm{p} 2+\mathrm{p} 3+\mathrm{p} 4$ & all five segments of the year \\
\hline $10 \mathrm{a}$ & $A N P P=p 0+p 1+p 2+p 3+p 4+p 1 * p 2+p 2 * p 3+p 3 * p 4$ & all five segments of the year, plus interactions \\
\hline 11 & $\mathrm{ANPP}=\mathrm{pt}$ & total yearly precipitation \\
\hline 12 & $\mathrm{ANPP}=\mathrm{pg}$ & total growing season precipitation \\
\hline
\end{tabular}




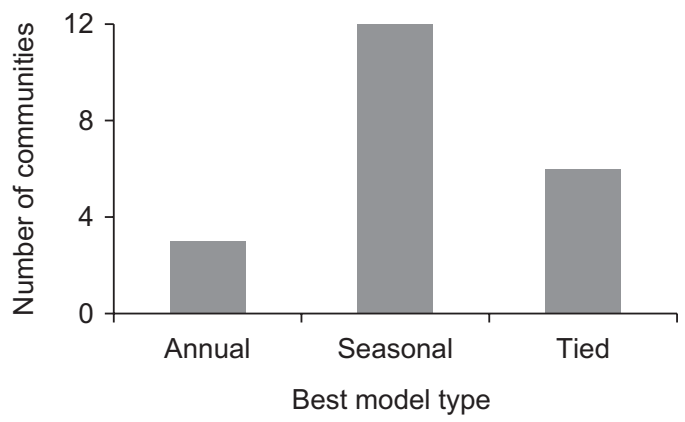

Figure 2. The distribution of best models for the communities by model type. Models within 2 AICc points of each other were considered 'tied'. extra variables. When we analyzed each community individually using our subset of 17 hypothesized models, we found that 21 of the 36 communities were statistically supported by models that explained annual variance in ANPP (see Table A1 for model results). In agreement with our general analysis, models that included some combination of seasonal variables generally outperformed models that only included annual precipitation (Fig. 2). Total annual precipitation alone (model 11) was the single best model in only three communities (JRN black grama grassland; SEV creosote shrubland; USE) although it was tied for best model in six additional communities (KNZ annually burned upland; KNZ annually burned lowland; KNZ upland burned every four years; SGS ridge,
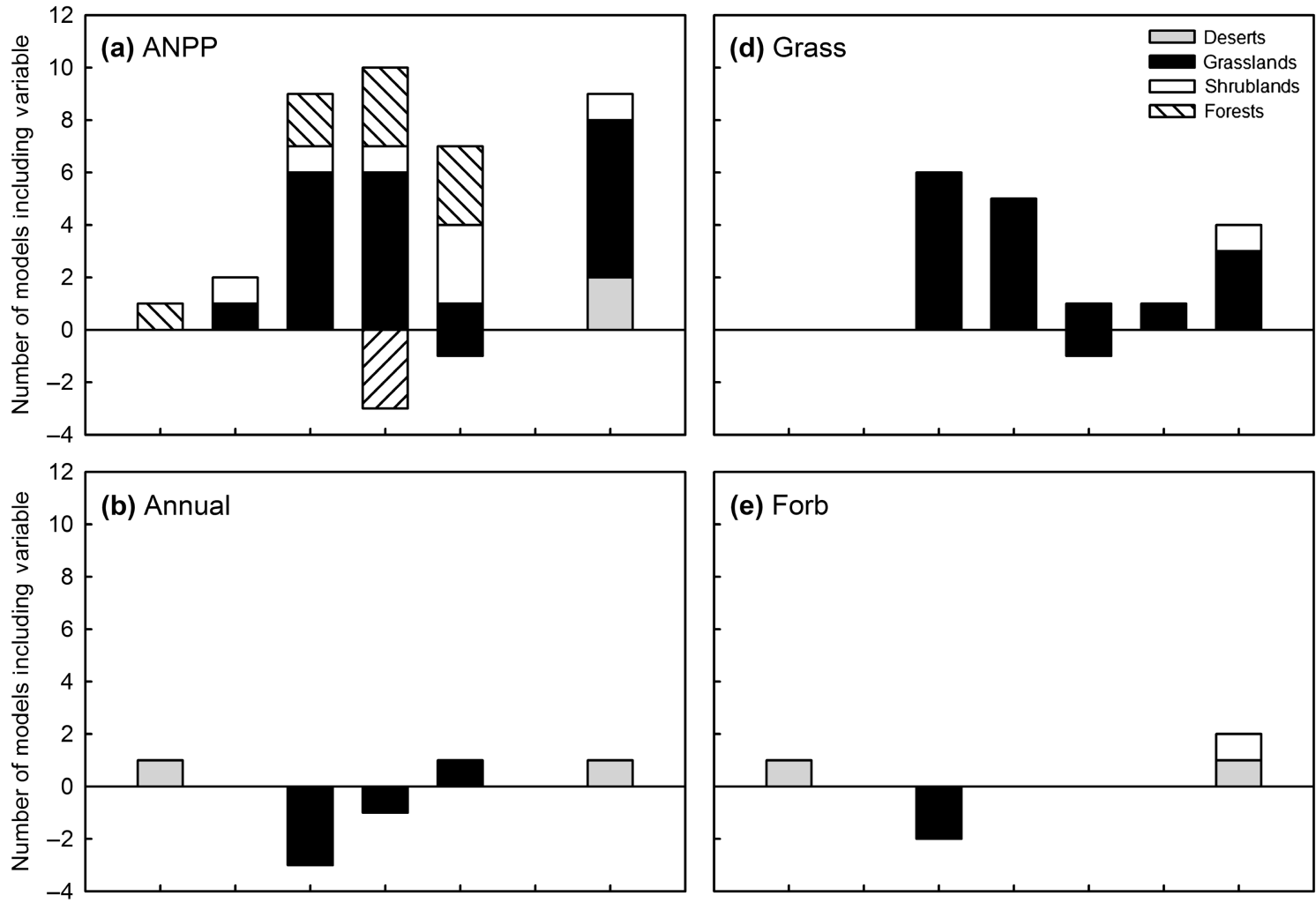

(e) Forb
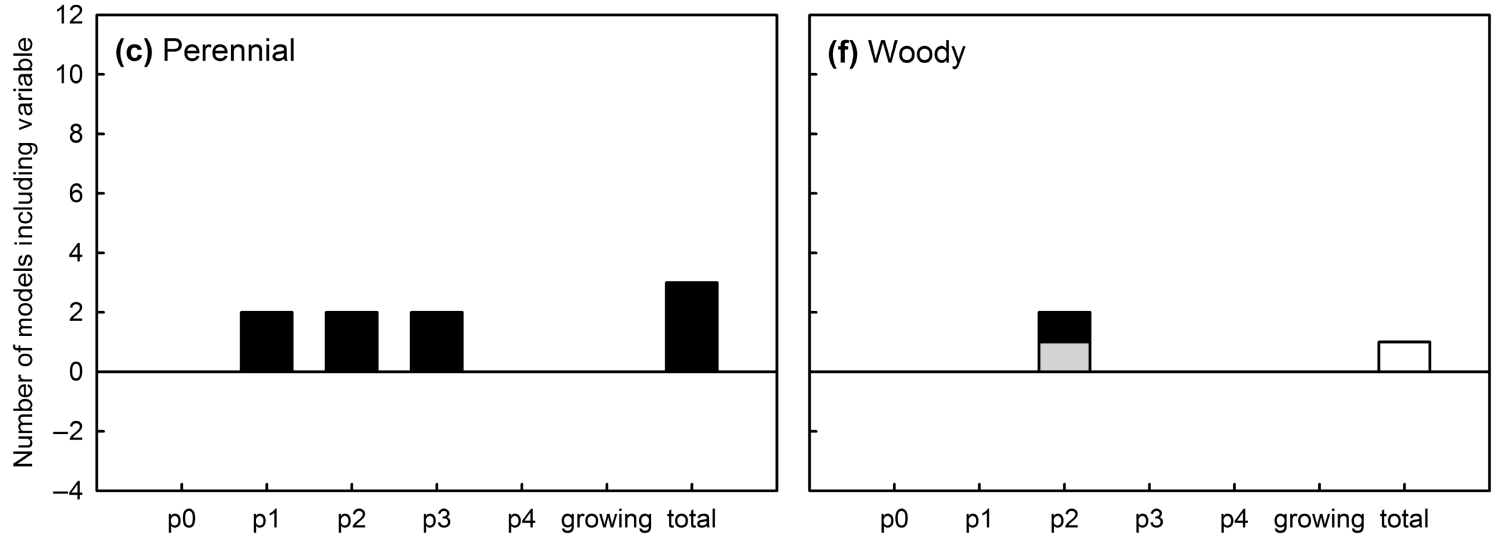

Figure 3. Breakdown of the significant $(\mathrm{p}<0.1)$ results across the different periods of precipitation tested in the models for $(a)$ total ecosystem ANPP, and where data were available, (b) annual, (c) perennial, (d) grass, (e) forb, (f) woody plant functional groups individually, at sites where such data were available (Table 1). The value on the $y$-axis is the number of models where a particular period was significant in the best model. Positive values indicate that the relationship between precipitation and ANPP was positive; negative values indicate that the relationship is negative. 


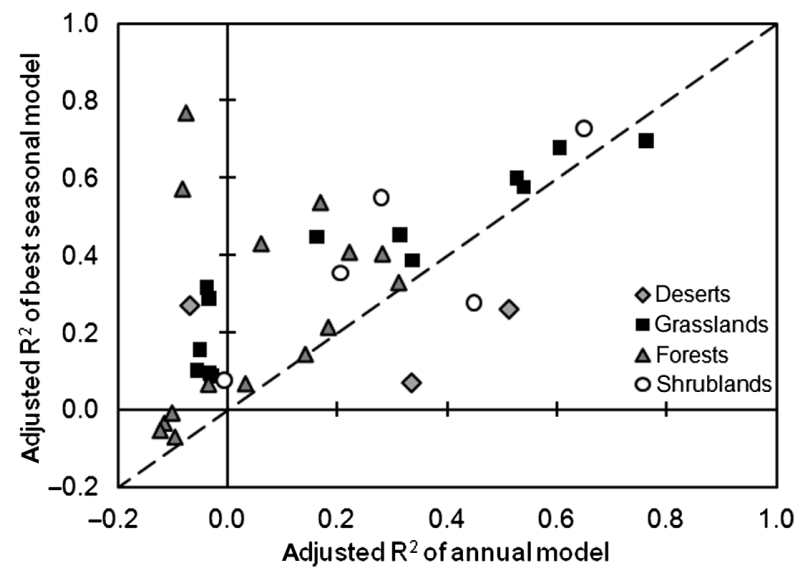

Figure 4. Comparison of the performance of the best seasonal model with a model that uses only total annual precipitation to predict ANPP. The dashed line indicates a 1:1 relationship (null hypothesis), above which ANPP is better predicted by seasonal precipitation and below which ANPP is better predicted by total annual precipitation.

midland, and swale; Fig. 2). The annual and seasonal ties along with ties between multiple seasonal models led to a total of 30 statistically supported models across the 21 communities.

Across all models, the impact of precipitation on ANPP was overwhelmingly positive (52 of 55 significant effects; Fig. 3). The best seasonal models often included more than one period ( $70 \%$ of seasonal models) and across the 30 best statistically supported models, the most common term included was mid-growing season precipitation (P3; significant in $47 \%$ of the best models), followed by early and late growing season precipitation (P2 and $\mathrm{P} 4$; significant in $38 \%$ and $32 \%$ of the best models, respectively, Fig. 3). Interactions were included in only 3 of the best models, and where significant they were always negative (Supplementary material Appendix A1 Table A1). The seasonal periods that significantly affected ANPP were not consistent across ecosystem type (Fig. 3), though it is worth noting that total annual precipitation and total growing season precipitation (models 11 and 12) were never the 'best' model in any forested system.

To assess the utility of seasonal precipitation data in predicting annual ANPP across all 36 communities, we compared the adjusted $\mathrm{R}^{2}$ of the best seasonal model from each community to the $\mathrm{R}^{2}$ of model 11 , which included only total annual precipitation (Fig. 4). In all but four communities examined (JRN black grama grassland, SEV creosote shrubland, SGS midland, USE) the seasonal model explained more variance than annual precipitation. In 19 of the communities, the improvement in adjusted $R^{2}$ in the seasonal model over model 11 was greater than 0.10 , and in 10 of the communities the improvement was greater than 0.20 (Fig. 4). Communities showing this greatest level of improvement when seasonal data were used to predict ANPP were found at BNZ (all), CVO, HOP, KBS (annually burned), KNZ (uplands and lowlands burned every 20 years), and SEV (black grama grassland). Across all sites, improvement in adjusted $\mathrm{R}^{2}$ did not correlate significantly with either the mean or the coefficient of variation (CV) of total annual precipitation (Fig. 5).

\section{Functional group responses to seasonal and annual precipitation}

In the seven communities where annual and perennial biomass were examined separately, production by annuals tended to be better explained by seasonal precipitation (four of five communities with significant models; Fig. 3, 6), while production by perennials responded more to total annual precipitation (three of four communities with significant models; Fig. 3, 6). In about half of the 14 communities with growth form data, precipitation and ANPP variation were correlated for grasses and forbs, but not for woody species. Grass production was correlated roughly equally with seasonal (three communities) and total annual precipitation (four communities; Fig. 3, 6) while forb production tended to be correlated with seasonal precipitation (four out of six communities where precipitation was significant). Precipitation models were only
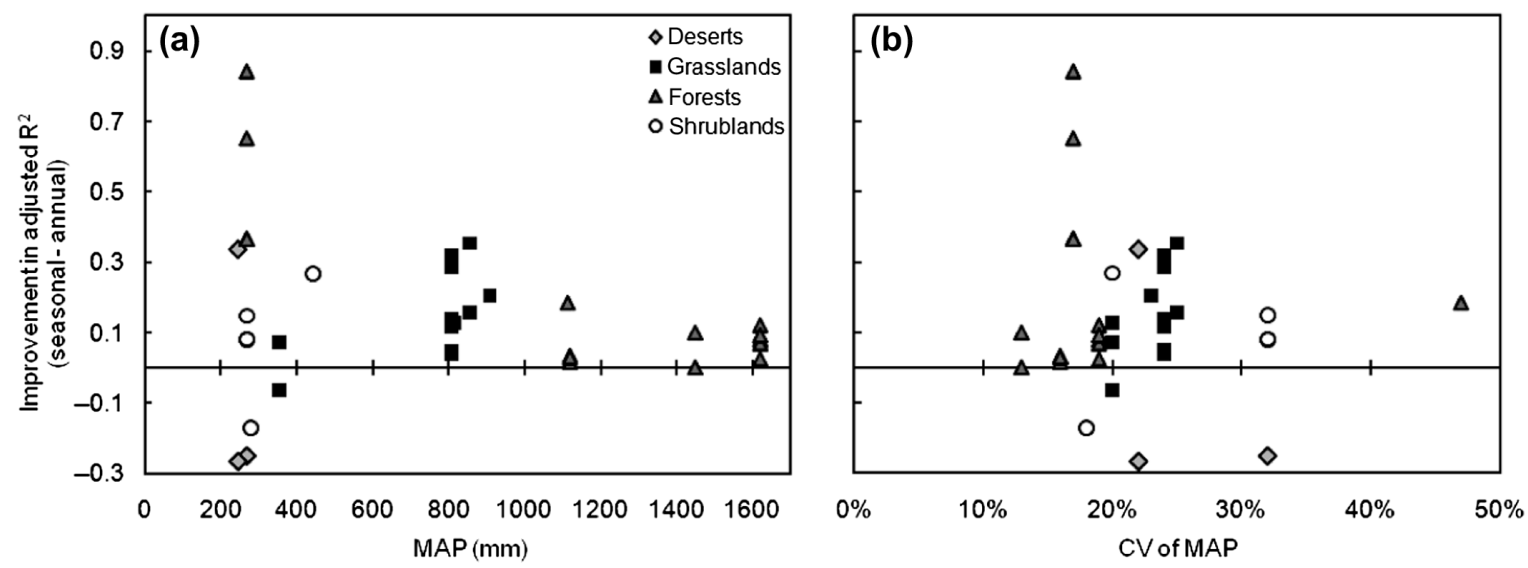

Figure 5. Improvement across all communities of the best seasonal model over the model including only total annual precipitation in predicting ANPP versus (a) mean annual precipitation and (b) the CV of annual precipitation. ANPP in communities with positive improvement values are better predicted by seasonal precipitation while ANPP in communities with negative improvement values are better predicted by total annual precipitation. 

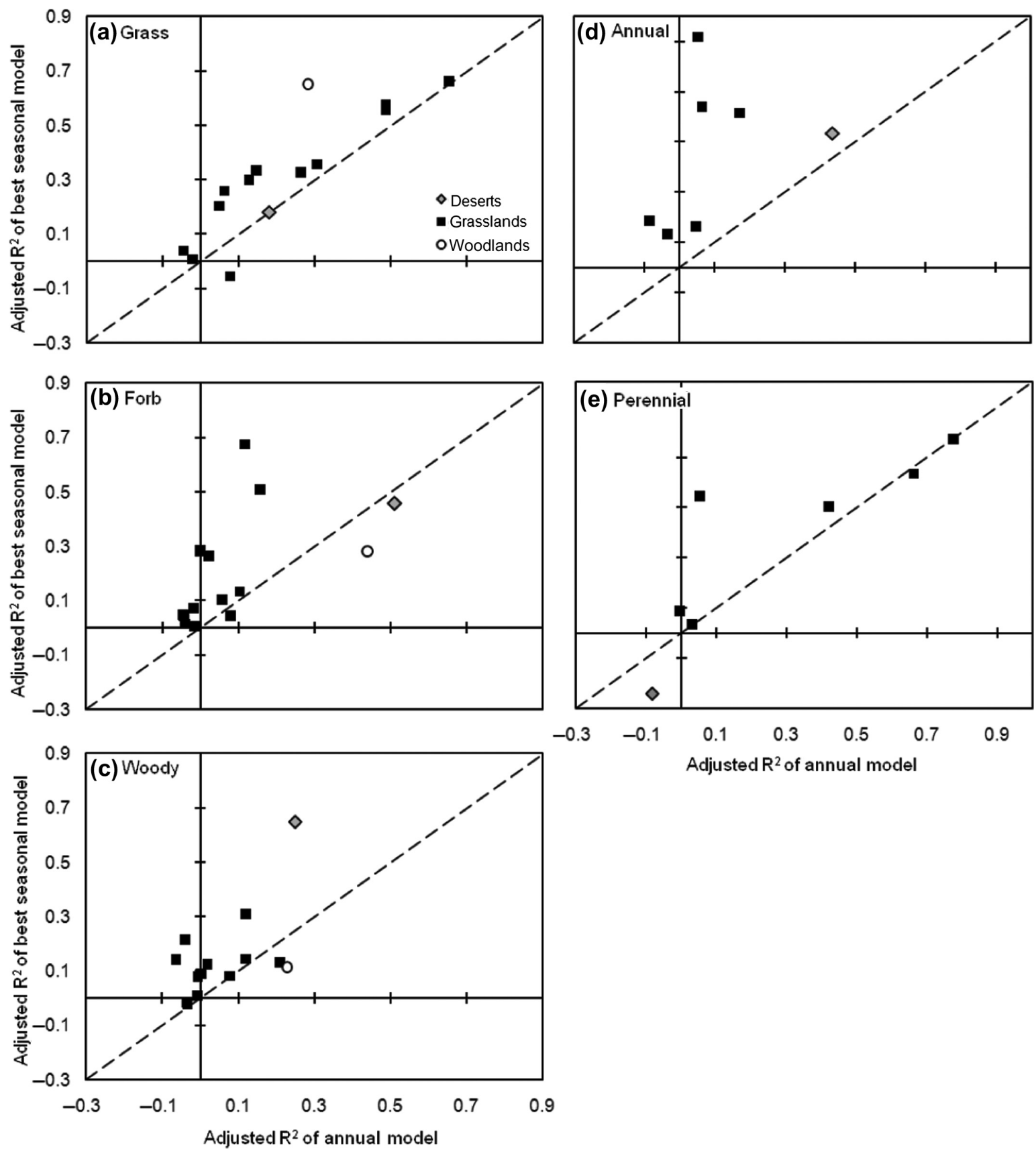

Figure 6. Comparison of the performance of the best seasonal model with a model that uses only total annual (plant-centric) precipitation to predict total-above ground biomass of (a) grasses, (b) forbs, (c) woody, (d) annual, and (e) perennial plants at sites where such data were available (Table 1). The dashed line indicates a 1:1 relationship, above which biomass is better predicted by seasonal precipitation and below which biomass is better predicted by total annual precipitation.

related to woody shrub production in two communities, with one seasonal and one total annual precipitation model (Fig. 3, 6). Interestingly, the same model (model 11) best explained all three functional groups in only one community (USE).

\section{Discussion}

Across the majority of our ecosystems, which ranged from deserts to forests, we found that seasonal precipitation described variation in ANPP as well or better than total precipitation. Our results go beyond previous site-specific work (Suttle et al. 2007) to demonstrate the generality and strength of the effects of variation in precipitation at sub-annual time scales on annual ANPP in a wide array of ecosystems.

\section{ANPP is more sensitive to seasonal precipitation than annual precipitation}

The majority of the best seasonal models showed that ANPP correlated significantly with only one or two periods of the 
growing season. Interestingly, though a number of the best seasonal models included multiple periods, including interactions between consecutive periods rarely improved their performance (Supplementary material Appendix A1 Table A1). We expected that in models including sequential time periods, if precipitation in the earlier period was low, the amount of precipitation in the later period would become more important to annual production. Conversely, if the earlier period had high precipitation, precipitation in the following period of the growing season would be less important. However, models that included consecutive periods independently, such as model 5 which included early and mid-season precipitation, had more statistical support than models that also included the interaction between those two periods (e.g. model 5a). Overall, our results showed few significant interactions between consecutive periods of the growing season.

While different seasonal periods rarely interacted, including multiple periods did improve model fit in most cases. Including multiple periods of the growing season without interactions could add explanatory power if plant growth is affected by precipitation in particular subsets of the growing season, as observed by Cable (1975) in desert grasslands and by Xiao et al. (1996) in semi-arid grasslands as well as in more mesic grasslands such as KNZ (La Pierre et al. 2011, Craine et al. 2012). This may be especially true if the growth is highly dependent on precipitation at one time, but still responds to precipitation in other periods at a lesser rate. If production is more sensitive to precipitation during one time period than another, a model that sums these two would underestimate the effect of precipitation in the important period and overestimate the effect in the less important period. For example, Milchunas et al. (1994) found that while production responded to both warm- and cool-season precipitation, production could respond more strongly to cool-season precipitation at SGS. Moreover, similar to results from our study, a study at JRN by Huenneke et al. (2002) found that grass production was greatest late in the monsoon season while creosote and mesquite shrub production peaked in the spring following winter precipitation in a Chihuahuan Desert grassland that is characterized by a bi-modal distribution of precipitation across a year.

\section{The response of ANPP to seasonal precipitation does not vary by ecosystem type}

While we found that models using seasonal precipitation variables improved our ability to account for variation in annual ANPP, ecosystem types did not consistently differ in which periods of the year mattered (Supplementary material Appendix A1 Table A1). Ecosystems ranging from semiarid grasslands to forests were all most sensitive to precipitation during one or more of the three periods of the growing season, but the improvement from using seasonal precipitation was similar across all ecosystem types and there was no specific period that was more closely associated with one ecosystem type over another. Our expectation was that forests would respond differently than other ecosystem types, with higher average precipitation preventing water limitation that could affect ANPP. It is important to note that our study included forested sites with both very high and low mean annual precipitation, and that the forested sites with higher mean annual precipitation (e.g. HBR) showed a smaller improvement than the forest site with the least precipitation (BNZ; Fig. 5a) when we used seasonal precipitation variables to predict ANPP. However, additional replication would be required to attribute this pattern among forests to differences in mean annual precipitation.

While previous work suggested that grassland production should change the most with variation in precipitation across years (Webb et al. 1978, 1983, Knapp and Smith 2001), our finding that seasonal models generally outperformed models using variation in annual precipitation shows that a wide array of ecosystems are sensitive to the distribution of precipitation within the growing season (Fig. 2, 4). The first two thirds of the growing season were most commonly important (Fig. 3), which may reflect ties to plant phenology and is consistent with previously published results from LTER grassland sites (La Pierre et al. 2011, Craine et al. 2012). Early precipitation may affect germination dynamics for annuals or the growth of plants like cool-season grasses, while precipitation a little later in the growing season may affect warm season grasses and forbs more (Xia et al. 2010). Regardless of the exact mechanism, our results indicate that future changes in the distribution of precipitation during the growing season will likely have important effects on ANPP across a wide range of ecosystems.

\section{Response to seasonal precipitation does not vary by functional groups}

We expected that plant functional groups would respond differentially to precipitation based on differences in physiology and life history, but our simple functional group divisions did not consistently increase the explanatory power of our models in the subset of sites analyzed. However, some interesting trends did emerge in communities where precipitation did correlate with functional group ANPP. For example annual species' biomass generally varied with seasonal precipitation while the biomass of perennials varied more with total annual precipitation. The ability of perennials to make use of water inputs across time makes sense given their deeper, more extensive, and more persistent rooting systems. In addition, they may mobilize stored resources to initiate rapid growth as soon as conditions are favorable, unlike an annual that must germinate and has a minimal initial biomass.

Our lack of consistent improvement in explaining ANPP using several broad functional groups is not unprecedented. While some researchers have found that using functional groups increased the amount of variation explained by precipitation (Jobbágy and Sala 2000), other work has found little support for this pattern (Briggs and Knapp 1995). Given the divergent results of previous studies and the lack of a common response in our analyses, it may be that very basic functional groupings such as annual/ perennial or grass/forb/shrub are too broad to be useful across multiple ecosystems. It also may be that our conservative criteria for model selection (AICc) and models that we considered biologically relevant (adjusted $R^{2} \geq 0.30$ ) 
also limited our results. Other studies focused on specific ecosystems could use less conservative metrics when analyzing one system, as compared to our multi-site analysis, or use more appropriate functional groups. For example, an analysis using $\operatorname{cool}\left(\mathrm{C}_{3}\right)$ and warm $\left(\mathrm{C}_{4}\right)$ season grasses, which have been shown to use different soil moisture pools at KNZ (Nippert and Knapp 2007), may have more success explaining the sensitivity of grassland ANPP to multiple parts of the growing season. It is also possible that functionalgroup data will need to be combined with information on community characteristics such as dominant species when functional groups do not respond consistently. System-specific knowledge about species interactions like nurse plants and other forms of facilitation may become more important as these interactions may allow for production by species that might not otherwise survive (i.e. Armas et al. 2011), thereby mediating responses to precipitation variability.

\section{Conclusions}

Here we used a simple method to partition precipitation throughout the year into five periods across a range of climate and ecosystem types. With this coarse metric and a broad definition of growing season length, our analyses show that including seasonal variation in future work examining the effects of precipitation variability may improve ANPP predictions. The summing of precipitation over both ecologically important and unimportant parts of the growing season in analyses using annual precipitation may partially explain why previous studies found a weaker relationship between inter-annual variation in precipitation and ANPP (Smoliak 1986, Briggs and Knapp 1995) than across spatial gradients in precipitation (Sala et al. 1988, Lauenroth and Sala 1992). Analyses that take advantage of specific system knowledge may allow investigators to determine more subtle patterns within a site, for example by tying the definition of the growing season more tightly to environmental factors. Examples could include temperature and moisture in arid areas, growing degree-days in colder ecosystems, or the timing of specific phenological stages (Richardson et al. 2010, La Pierre et al. 2011), which may respond differently to precipitation (Robinson and Gross 2010). Lagged effects of the previous year's weather conditions may also be important in some systems (Lane et al. 1993), though we did not have the statistical power to test such effects. Such site-specific analyses could also test specific combinations of periods not considered here that might be relevant for a particular system, for example using only two periods in a system with bi-modal precipitation patterns. Overall, using site-specific biological knowledge is likely to provide more distinctive and meaningful seasonal periods, but even a coarse definition that allows comparisons across a range of very different ecosystems can improve our understanding of variation in ANPP.

While we have shown that ANPP responds to precipitation on a seasonal scale more commonly than previously thought, our results raise several questions. What separates ecosystems that show a weak correlation between ANPP and seasonal precipitation from those that show a strong correlation with seasonal precipitation? Additionally, what causes certain ecosystems to be sensitive to one part of the growing season compared to another? Potential explanations include interactions with both abiotic (i.e. nutrients and temperature) and biotic (i.e. herbivory and competition) factors that may limit production.

Our results were often congruent with previous sitespecific studies, yet there were also some important discrepancies that show the importance of site-specific research. For example, at our annual grassland site (HOP), we found no relationship between ANPP and precipitation, yet previous research at the site found strong precipitation effects (Murphy 1970). However, the relationship revolved around precipitation in only one month (November) so it is likely that the length of our growing season periods were too long to recreate these results. For that site our generalized approach fell short. In other instances, our results generally matched previous results, for example like Milchunas et al. (1994) at SGS we found that precipitation mattered, but did not always find the strong support they did for separating cool and warm season precipitation (Supplementary material Appendix A1 Table A1). However, in the most supported seasonal models the earlier cool season regression coefficients were generally larger than the later warm season coefficients, consistent with Milchunas et al.'s (1994) finding that cool season precipitation had a larger impact on ANPP than warm season precipitation. At JRN, our results and previous research both found a relationship between ANPP and precipitation (Huenneke et al. 2002) across multiple communities. However, while we found evidence that shrub communities responded to seasonal precipitation (Fig. 4, 5, Supplementary material Appendix A1 Table A1), we did not find the strong early season signal that Huenneke et al. (2002) did. One reason for this discrepancy may be that we used annual ANPP measurements while Huenneke et al. (2002) measured production at three points during the year to quantify seasonal production. Overall, while site-specific studies often captured a more nuanced picture of the patterns at a given site, our simplified analysis was able to capture a reasonably accurate picture across a broad range of ecosystems.

Although precipitation provides a convenient and widely available metric, the effect of a precipitation event on a plant community depends on a number of abiotic and biotic factors that affect how precipitation translates into plant-available soil moisture (Weltzin et al. 2003, Schwinning and Sala 2004). For example, differences in soil texture and structure (Sala et al. 1988, Loik et al. 2004), plant litter (Deutsch et al. 2010), or antecedent soil moisture conditions (Rawls et al. 1993) will influence the changes in soil moisture that result from a precipitation event. While beyond the scope of this study, research also indicates that landscape position (run-on/off) and soil properties may be a more important driver of ANPP in ecosystems like deserts than precipitation alone (Huenneke et al. 2002, Muldavin et al. 2008, Sponseller et al. 2012). While not as commonly available as long-term time series, soil moisture data can relate more directly to plant growth and help explain patterns in ANPP (Nippert et al. 2006, Muldavin et al. 2008). Differences in ANPP measurement methodology among sites and ecosystem types may obscure 
some patterns, particularly in the forest and woodland sites where data sets describing woody biomass and foliar production were not both available (CVO, CWT, TEA) or could not be combined (HBR, HFR). While our study focused on aboveground biomass responses, future work should also attempt to account for belowground responses to precipitation such as root production, and soil respiration (Hui and Jackson 2006, Fay et al. 2008, Thomey et al. 2011) as more long-term data becomes available. Predicted shifts in storm intensity and frequency (Easterling et al. 2000, Diffenbaugh et al. 2005, IPCC 2007) which may independently affect communities (Knapp et al. 2008, Robinson and Gross 2010) will make it more important than ever to factor in how abiotic and biotic factors affect the transition from precipitation to plant-available soil moisture.

The results of our study have implications for predictions of future ANPP under a changing climate. One of the primary shifts in climate predicted by the Intergovernmental Panel on Climate Change is that higher temperatures will lead to an overall increase in growing season length across North America (IPCC 2007). Our results show that many ecosystem types are sensitive to the timing of precipitation with respect to their growing seasons. If changes in growing season length are not accompanied by a shift in the timing of precipitation, the result may be large changes in production. For example, Ma et al. (2008) showed how temperature and precipitation interacted in a Mongolian grassland by observing higher mean annual biomass when both temperature and pre-season precipitation were higher, but lower mean annual biomass when temperature alone was higher. Likewise, Xia and Wan (2012) found that while increased nighttime temperature resulted in longer growing season length, it was actually changes in accumulated precipitation that explained a large portion (48\%) of the variation in changes in species percent coverage. The overall warming predicted for North America may make the seasonal interactions seen in our data even more important in determining production in the future.

Based on our analyses, one ecosystem that might be affected would be the eastern deciduous forest if summers in North America become longer and drier (IPCC 2007). The two temperate forest sites with significant models (Coweeta and Harvard Forest) showed the greatest sensitivity to precipitation received in the middle of their growing season, when evapotranspirative demand is generally greatest and precipitation is predicted to decrease. Even though mean annual precipitation is predicted to increase for most of North America, greater variability and uncertainty about the timing of these future events makes the net effect of increased precipitation on production uncertain. In addition, it is unclear how seasonal precipitation may interact with concurrent anthropogenic changes to the environment such as nitrogen deposition, increased ambient $\mathrm{CO}_{2}$ and $\mathrm{O}_{3}$, non-native species invasions, and disturbance regimes (Barger et al. 2011, Vargas et al. 2012). Further research to determine how changes in seasonal precipitation interact with chronic resource alteration and more variable weather would be worthwhile.

Quantifying and predicting ANPP is crucial for our understanding of the carbon cycle and the management of ecosystems. Many studies relating ANPP and precipitation examine how precipitation affects ANPP on an annual timescale, but there is a growing body of site-specific studies that find a stronger relationship with seasonal precipitation (Lauenroth and Sala 1992, Milchunas et al. 1994, Briggs and Knapp 1995, Jobbágy and Sala 2000, Knapp et al. 2006, Chou et al. 2008, Muldavin et al. 2008). However, we lack a cross-ecosystem understanding of the relationship between seasonal precipitation and ANPP. Our work examining long-term data sets across a variety of ecosystems in North America indicates that seasonal precipitation patterns often play an important role in determining ANPP. Indeed, most of the ecosystems in our study were more responsive to precipitation during specific portions of the growing season than to annual or growing season totals. While the 2007 IPCC reports project increased NPP across North America due to predictions of longer growing seasons, our findings indicate that understanding this relationship may require further work. If changes in temperature are not accompanied by precipitation at the appropriate time, ANPP may not follow the anticipated trend. Incorporating a more thorough understanding of how seasonal precipitation patterns affect ANPP is necessary to advance our understanding of ANPP dynamics and improve predictions of how climate change will affect ANPP.

Acknowledgements - This work was supported by a LTER network synthesis grant. The authors thank Scott Collins and William Lauenroth for comments on previous drafts of this manuscript and Steven Rostkowski for his input in project design and assistance with data processing. The authors would also acknowledge the following NSF LTER sites for providing data: BNZ, CDR, CWT, HBR, HFR, JRN (in particular J. Yao), KBS, KNZ SEV, SGS. CVO data are archived by NOAA paleoclimatology program, and the TEA data were provided by Malcolm North at the US Forest Service PSW Research Station. Converted data from Murphy, 1970 for HOP came from Joanna Hsu at UC Berkeley, and Dr. Peter Alder (Utah State Univ.) provided us with converted data from Blaisdell 1958 for USE. This is KBS contribution number 1699 .

\section{References}

Armas, C. et al. 2011. A field test of the stress-gradient hypothesis along an aridity gradient. - J. Veg. Sci. 22: 818-827.

Baker, B. B. et al. 1993. The potential effects of climate-change on ecosystem processes and cattle production on US rangelands. - Climate Change 25: 97-117.

Barger, N. N. et al. 2011. Woody plant proliferation in North American drylands: a synthesis of impacts on ecosystem carbon balance. - J. Geophys. Res. 116, G00K07, doi: 10.1029/2010JG001506.

Briggs, J. M. and Knapp, A. K. 1995. Interannual variability in primary production in tallgrass prairie: climate, soil moisture, topographic position, and fire as determinants of aboveground biomass. - Am. J. Bot. 82: 1024-1030.

Burnham, K. P. and Anderson, D. R. 2002. Model selection and multi-model inference, 2 nd edn. - Springer.

Cable, D. R. 1975. Influence of precipitation on perennial grass production in the semidesert southwest. - Ecology 56: 981-986.

Chou, W. W. et al. 2008. The sensitivity of annual grassland carbon cycling to the quantity and timing of rainfall. - Global Change Biol. 14: 1382-1394. 
Craine, J. M. et al. 2012. Precipitation timing and grazer performance in a tallgrass prairie. - Oikos. doi:10.1111/j.1600-0706. 2012.20400.x

Deutsch, E. S. et al. 2010. Separation of grassland litter and ecosite influences on seasonal soil moisture and plant growth dynamics. - Plant Ecol. 209: 135-145.

Diffenbaugh, N. S. et al. 2005. Fine-scale processes regulate the response of extreme events to global climate change. - Proc. Natl Acad. Sci. USA 102: 5774-15778.

Easterling, D. R. et al. 2000. Climate extremes: observations, modeling and impacts. - Science 289: 2068-2074.

Fay, P. A. et al. 2002. Altered rainfall patterns, gas exchange, and growth in grasses and forbs. - Int. J. Plant Sci. 163: 549-557.

Fay, P. A. et al. 2008. Changes in grassland ecosystem function due to extreme rainfall events: implications for responses to climate change. - Global Change Biol. 14: 1600-1608.

Heisler-White, J. L. et al. 2009. Contingent productivity responses to more extreme rainfall regimes across a grassland biome. - Global Change Biol. 15: 2894-2904.

Huenneke, L. F. et al. 2001. Spatial heterogeneity in Chihuahuan Desert vegetation: implications for sampling methods in semi-arid ecosystems. - J. Arid Environ. 47: 257-270.

Huenneke, L. F. et al. 2002. Desertification alters patterns of aboveground net primary production in Chihuahuan ecosystems. - Global Change Biol. 8: 247-264.

Hui, D. and Jackson, R. B. 2006. Geographical and interannual variability I biomass partitioning in grassland ecosystems: a synthesis of field data. - New Phytol. 169: 85-93.

Huxman, T. E. et al. 2004. Convergence across biomes to a common rain-use efficiency. - Nature 429: 651-654.

IPCC 2007. Climate change 2007: the physical science basis. Summary for policymakers. - Cambridge Univ. Press.

Jobbágy, E. G. and Sala, O. E. 2000. Controls of grass and shrub aboveground production in the Patagonian steppe. - Ecol. Appl. 10: 541-549.

Knapp, A. K. and Smith, M. D. 2001. Variation among biomes in temporal dynamics of aboveground primary production. - Science 291: 481-484.

Knapp, A. K. et al. 2006. Convergence and contingency in production-precipitation relationships in North American and south african C-4 grasslands. - Oecologia 149: 456-464.

Knapp, A. K. et al. 2008. Consequences of more extreme precipitation regimes for terrestrial ecosystems. - BioScience 58: 811-821.

La Pierre, K. J. et al. 2011. Explaining temporal variation in aboveground productivity in a mesic grassland: the role of climate and flowering. - J. Ecol. 99: 1250-1262.

Lane, C. J. et al. 1993. Width of sugar maple (Acer saccharum) tree rings as affected by climate. - Can. J. For. Res. 23: 2370-2375.

Lauenroth, W. K. and Sala, O. E. 1992. Long-term forage production of North American shortgrass steppe. - Ecol. Appl. 2: 397-403.

Leith, H. and Whittaker, R. J. (eds) 1975. Primary productivity of the biosphere. - Springer.

Loik, M. E. et al. 2004. A multi-scale perspective of water pulses in dryland ecosystems: climatology and ecohydrology of the western USA. - Oecologia 141: 269-281.

$\mathrm{Ma}, \mathrm{W}$. H. et al. 2008. Above- and belowground biomass in relation to environmental factors in temperate grasslands, Inner Mongolia. - Sci. China Ser. C Life Sci. 51: 263-270.

McNaughton, S. J. et al. 1989. Ecosystem-level patterns of primary productivity and herbivory in terrestrial habitats. - Nature 341: 142-144.

Milchunas, D. G. et al. 1994. Productivity of long-term grazing treatments in response to seasonal precipitation. - J. Range Manage. 47: 133-139.
Motha, R. P. and Baier, W. 2005. Impacts of present and future climate change and climate variability on agriculture in the temperate regions: North America. - Climate Change 70: 137-164.

Muldavin, E. H. et al. 2008. Aboveground net primary production dynamics in a northern Chihuahuan Desert ecosystem. - Oecologia 155: 123-132.

Murphy, A. H. 1970. Predicted forage yield based on fall precipitation in California annual grasslands. - J. Range Manage. 23: 363-365.

Newman, G. S. et al. 2006. Above- and belowground net primary production in a temperate mixed deciduous forest. - Ecosystems 9: 317-329.

Nippert, J. B. and Knapp, A. K. 2007. Linking water uptake with rooting patterns in grassland species. - Oecologia 153: 261-272.

Nippert, J. B. et al. 2006. Intra-annual rainfall variability and grassland productivity: can the past predict the future? - Plant Ecol. 184: 65-74.

Notaro, M. et al. 2010. Complex seasonal cycle of ecohydrology in the southwest United States. - J. Geophys. Res. Biogeosci. 115 doi:10.1029/2010JC006261.

Ogle, K. and Reynolds, J. F. 2004. Plant responses to precipitation in desert ecosystems: integrating functional types, pulses, thresholds and delays. - Oecologia 141: 282-294.

Rawls, W. J. et al. 1993. Infiltration and water movement. - In: Maidment, D. R. (ed.), Handbook of hydrology. McGraw-Hill, pp. 1-51.

Richardson, A. D. et al. 2010. Influence of spring and autumn phonological transitions on forest ecosystem productivity. - Phil. Trans. R. Soc. B 365: 3227-3246.

Robertson, T. et al. 2010. Precipitation magnitude and timing differentially affect species richness and plant density in the sotol grassland of the Chihuahuan Desert. - Oecologia 162: 185-197.

Robinson, T. M. P. and Gross, K. L. 2010. The impact of altered precipitation variability on annual weed species. - Am. J. Bot. 97: 1-5.

Rosenzweig, M. 1968. Net primary productivity of terrestrial communities - prediction from climatological data. - Am. Nat. 102: 67-74.

Sala, O. E. and Austin, A. T. 2000. Methods of estimating aboveground net primary production. - In: Sala, O. E. et al. (eds), Methods in ecosystem science. Springer, pp. 31-43.

Sala, O. E. et al. 1988. Primary production of the central grassland region of the USA. - Ecology 69: 40-45.

Schenk, H. J. and Jackson, R. B. 2002. Rooting depths, lateral root spreads and below-ground/above-ground allometries of plants in water-limited ecosystems. - J. Ecol. 90: 480-494.

Schimel, D. S. et al. 2001. Recent patterns and mechanisms of carbon exchange by terrestrial ecosystems. - Nature 414: 169-172.

Schoof, J. T. et al. 2010. Development of daily precipitation projections for the United States based on probabilistic downscaling. - J. Geophys. Res. Atmospheres 115 D13106, doi:10.1029/2009JD013030.

Schwinning, S. and Sala, O. E. 2004. Hierarchy of responses to resource pulses in and and semi-arid ecosystems. - Oecologia 141: 211-220.

Smoliak, S. 1986. Influence of climatic conditions on production of Stipa bouteloua prairie over a 50-year period. - J. Range Manage. 39: 100-103.

Sponseller, R. A. et al. 2012. Variation in monsoon precipitation drives spatial and temporal patterns of Larrea tridentata growth in the Sonoran Desert. - Funct. Ecol. doi: 10.1111/j.13652435.2012.01979.x

Suttle, K. B. et al. 2007. Species interactions reverse grassland responses to changing climate. - Science 315: 640-642. 
Thomey, M. L. et al. 2011. Effect of precipitation variability on net primary production and soil respiration in a Chihuahuan Desert grassland. - Global Change Biol. 17: 1505-1515.

Vargas, R. et al. 2012. Precipitation variability and fire influence the temporal dynamics of soil $\mathrm{CO}_{2}$ efflux in an arid grassland. - Global Change Biol. 18: 1401-1411.

Vermeire, L. T. et al. 2009. Primary productivity and precipitationuse efficiency in mixed-grass prairie: a comparison of northern and southern US Sites. - Rangeland Ecol. Manage. 62: 230-239.

Walter, H. 1979. Vegetation of the Earth. - Springer.

Webb, W. L. et al. 1978. Primary productivity and water-use in native forest, grassland and desert ecosystems. - Ecology 59: 1239-1247.

Webb, W. L. et al. 1983. Primary production and abiotic controls in forests, grasslands and desert ecosystems in the United States. - Ecology 64: 134-151.

Supplementary material (available as Appendix O20655 $<$ www.oikosoffice.lu.se/appendix $>$ ). Appendix A1.
Weltzin, J. F. et al. 2003. Assessing the response of terrestrial ecosystems to potential changes in precipitation. - BioScience 53: 941-952.

Xia, J. and Wan, S. 2012. The effects of warming-shifted plant phenology on ecosystem carbon exchange are regulated by precipitation in a semi-arid grassland. - PLoS One 7(2): e32088.

Xia, Y. et al. 2010. Aboveground production and species richness of annuals in Chihuahuan Desert grassland and shrubland plant communities. - J. Arid Environ. 74: 378-385.

Xiao, X. M. et al. 1996. Temporal variation in aboveground biomass of Leymus chinense steppe from species to community levels in the Xilin River basin, Inner Mongolia, China. - Vegetatio 123: 1-12.

Yang, H. J. et al. 2011. Community structure and composition in response to climate change in a temperate steppe. - Global Change Biol. 17: 452-465. 